\title{
When a patient suspected with juvenile idiopathic arthritis turns out to be diagnosed with an infectious disease - a review of Lyme arthritis in children
}

\author{
Krzysztof Orczyk, Joanna Świdrowska-Jaros and Elżbieta Smolewska* [D
}

\begin{abstract}
The Lyme arthritis is a common manifestation of infection with Borrelia burgdorferi spirochete. Despite its infectious background, the inflammation clinically and histopatologically resembles juvenile idiopathic arthritis. As it affects a considerable number of Lyme disease patients, it should be routinely considered in differential diagnosis. Development of arthritis is partially dependent on spirochetal factors, including the ribosomal spacer type and the sequence of outer surface protein C. Immunological background involves Th1-related response, but IL-17 provides an additional route of developing arthritis. Autoimmune mechanisms may lead to antibiotic-refractory arthritis. The current diagnostic standard is based on a 2-step testing: ELISA screening and immunoblot confirmation. Other suggested methods contain modified two-tier test with C6 ELISA instead of immunoblot. An initial 28-day course of oral antibiotics (doxycycline, cefuroxime axetil or amoxicillin) is a recommended treatment. Severe cases require further anti-inflammatory management. Precise investigation of new diagnostic and therapeutic approaches is advisable.
\end{abstract}

Keywords: Lyme arthritis, Lyme disease, Pathogenesis, Symptoms, Treatment

\section{Background}

Lyme arthritis (LA) is a feature of late stage infection with the tick-borne spirochete, Borrelia burgdorferi (B. burgdorferi). It usually occurs weeks to months after the initial tick bite and may be preceded by erythema migrans (EM) [1]. This erythematous patch with a characteristic central clearing forming a typical "bull's eye lesion" is considered to be a pathognomonic manifestation of Lyme disease (LD) [2]. However, there is a growing body of evidence that the earlier stage of the infection frequently tends to remain asymptomatic and arthritis is becoming the presenting manifestation of the disease [3].

Steere et al. were the first to describe LD in Lyme, Connecticut, the United States, in patients initially suspected of juvenile idiopathic arthritis (JIA) [4]. Thorough diagnostic process in the aforementioned group revealed that reported episodes of arthritis were provoked by a

\footnotetext{
* Correspondence: e.smolewska@wp.pl

Department of Pediatric Rheumatology, Medical University of Lodz, Sporna 36/50, 91-738 Lodz, Poland
}

novel infectious trigger [5]. To date, there are 20 identified genospecies of $B$. burgdorferi sensu lato [6]. Nine of them infect humans: $B$. burgdorferi sensu stricto, B. garinii, B. afzelii, B. bavariensis, B. bissetii, B. kurtenbachii, B. lusitaniae, B. spielmanii, B. valaesiana [7]. The highest arthrogenic potential is presented by $B$. burgdorferi sensu stricto [8]. It induced arthritis in $46 \%$ of infected patients in the United States observed by Cerar et al. [9]. Its immunogenicity plays a crucial role in differences in clinical course of spirochetal infection between the United States, where B. burgdorferi sensu stricto is the main etiological factor of LD [10], and Europe, which is dominated by two other genospecies: $B$. garinii and $B$. afzelii [11]. As reported by Cerar et al. who assessed clinical images of LD in Slovenia, patients infected with B. garinii and B. afzelii developed arthritis in 18 and $15 \%$, respectively [9]. According to Kocbach et al., $B$. garinii infection frequently produces neurological symptoms and patients infected with $B$. afzelii regularly present with fatigue and myalgia [8]. 


\section{Epidemiology}

LD usually affects people in northern hemisphere [12]. The highest incidence in Europe was reported in southern Sweden $(464 / 100,000)$ [13]. Sykes et al. calculated average incidence rate in Western Europe as 22,05/ 100,000 , what results in approximately 230,000 of cases in Western Europe per year [14]. In the United States, The Centers for Disease Control and Prevention (CDC) reported nearly 30,000 of cases of LD in 2008 [15], whereas a survey regarding LD testing performed by large commercial laboratories gave a result of estimated 300,000 of cases per year [16].

There is a tendency towards an upswing in incidence of LD in the last few years [17]. Incidence rate reported in Poland in 2014 was $36 / 100,000$ and it was $52,9 \%$ higher than median from years 2008-2012 [18]. It is caused not only by better awareness of the disease and changes in human recreational behavior, but also by dispersion of reservoir hosts [19]. Colonization of urban areas in Poland by blackbirds [6] may provide a potential explanation, as one of the genospecies which dominate in Europe, B. garinii, most commonly affects birds [20].

There are two peaks of age in incidence of spirochetal infection. Most cases of LD are reported in age groups which spend more time outdoors near the natural reservoirs of ticks, specifically children between 5 and 9 years of age and adults $>50$ years [21]. Period between tick bite and its removal is considered to be a pivotal risk factor for infection [22], which is more likely to occur if a tick remains attached to the skin for more than first $24 \mathrm{~h}$ after bite [23]. Owning dogs has been also considered as a potential risk factor for LD, but Aenishaenslin et al. did not find significantly higher risk of tick bites in dog owners [24].

LA affects $3-15 \%$ of LD patients in Europe [25]. As for the United States, CDC reported LA in 33\% of LD patients diagnosed in 2001 and 2002 [26]. LD caused $51 \%$ of pediatric knee arthritis (341 out of 673 patients) observed by Deanehan et al. [27] and 5,2\% of pediatric hip arthritis (20 out of 385 patients) reported by Bachur et al. [28]. Therefore it is frequent enough to be included in differential diagnosis, which should consider other inflammatory arthritides, such as reactive arthritis and JIA (including psoriatic arthritis). Autoinflammatory arthritis may also develop within months after LD, presumably triggered by the spirochetal infection [3].

\section{Clinical features}

EM (Fig. 1), a characteristic sign mentioned above as a common initial manifestation of B. burgdorferi infection, is frequently accompanied, or sometimes preceded, by systemic symptoms, in particular fatigue, fever, headache, stiff neck, myalgias, arthralgias, nausea and dysesthesia [29]. However, according to Glaude et al.,

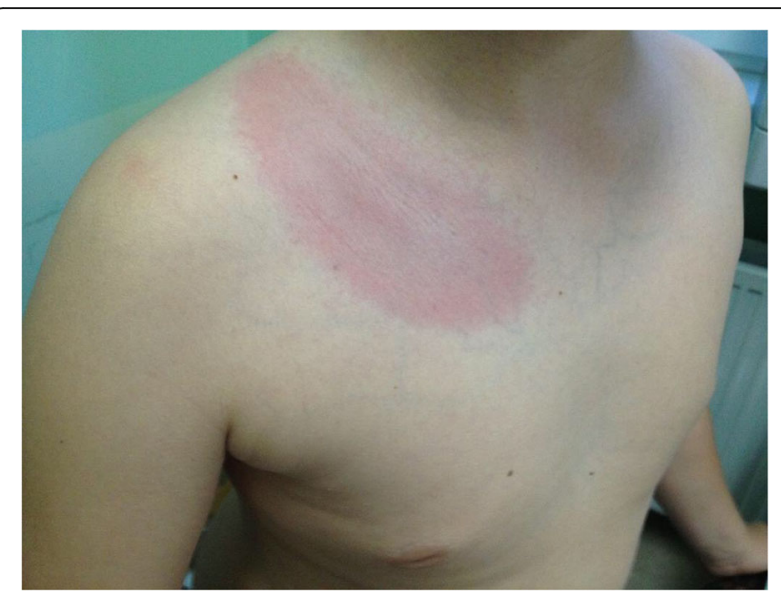

Fig. 1 Erythema migrans in a 9-year-old boy after tick bite

the majority (72\%) of patients observed in Canada had arthritis as their first symptom of LD. 76\% of patients did not recall a tick bite, and only $18 \%$ of patients had previous EM [30].

In patients who developed EM, arthralgias appeared 1 day to 8 weeks after onset of rash in a study of 55 patients performed by Steere et al. [31]. When EM is absent, symptoms of LA may occur months or even years after initial tick bite [32]. Therefore, it can be manifested in every month of the year, not only within time of increased outdoor activity [33]. In accordance with aforementioned diversity of genospecies, LA observed in Europe (caused mainly by B. garinii and B. afzelii) tends to occur in shorter period after initial tick bite comparing to B. burgdorferi sensu stricto infections [9].

On clinical presentation, LA usually affects large synovial joints asymmetrically [34]. Recurrent swelling of the affected joint with a presence of moderate inflammatory effusion is a common clinical finding in children suspected of LA [35]. Although more acute presentation may mimic septic arthritis, pain of the affected joints reported in patients with LA is usually less severe [27]. All patients reported by Huppertz et al. experienced joint swelling or limitation of range of motion, but no pain [36]. Additionally, 38\% of patients assessed by Thompson et al. were incapable of bearing weight on the affected limb [37].

The knee is affected (Fig. 2) in over 90\% of cases [38]. The ankle is found to be the second most commonly involved joint [38]. Correspondingly, the clinical image can resemble a mono- or oligoarticular JIA. Still, polyarticular involvement should not automatically exclude LA. Sá et al. reported a case of a 6-year-old girl with serological confirmation of spirochetal infection who developed swelling of the proximal inter-phalangeal joints of hands and wrist and both tibiotarsal joints within several months after initial tick bite and was finally diagnosed with polyarticular JIA [39]. 


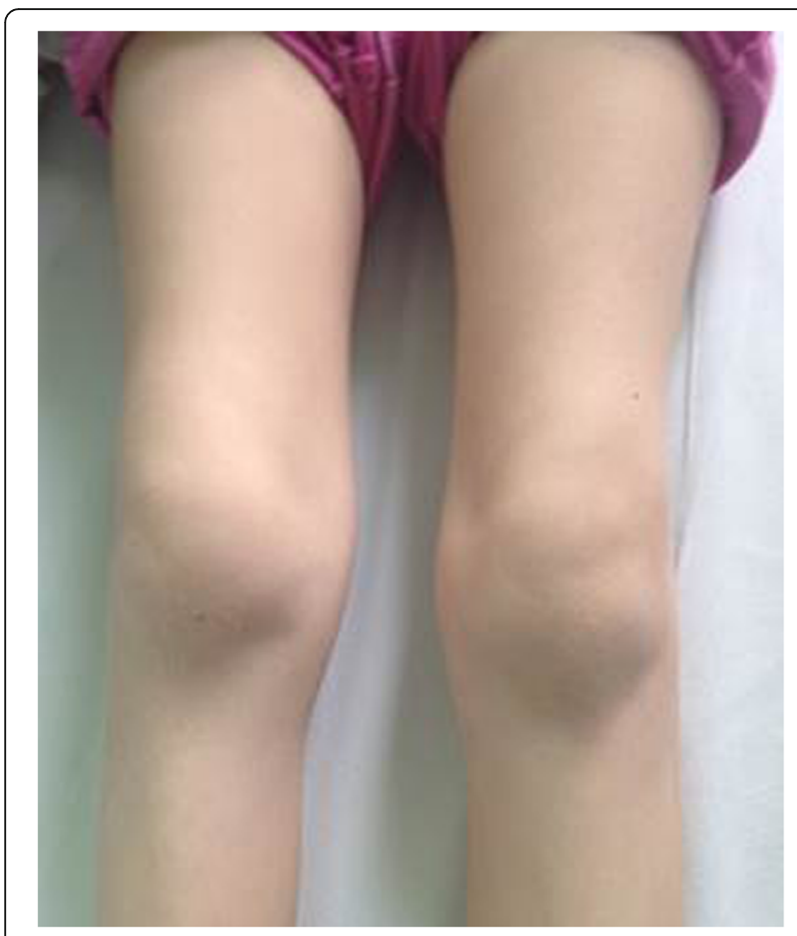

Fig. 2 Bilateral knee arthritis in a serological-positive (Borrelia burgdorferi) 6-year-old girl

LA that does not recover during first 3 months after initiation of recommended treatment regimens (described below) has been referred to as antibiotic-refractory LA $[36,40]$. In a study published by Tory et al. $23 \%$ of pediatric patients had persistent synovitis after 8 weeks of oral antibiotic therapy or 4 weeks of intravenous therapy or both [41]. LA eventually resolves spontaneously, but this may take even 8 years in extreme cases [42].

\section{Spirochetal factors of inflammation}

The $B$. burgdorferi genome has a unique structure. More than $40 \%$ of genetic material is located in linear and circular plasmids therefore spirochetes are able to rapidly adapt to new environmental conditions [43]. B. burgdorferi genotypes are classified on the basis of the 16S-23S ribosomal spacer type (RST) and the sequence of outer surface protein $\mathrm{C}(\mathrm{OspC})$ [9]. RST1 strains are more likely to cause disseminated $B$. burgdorferi infection, whereas RST2 and RST3 strains are less frequently detected peripherally. Moreover, RST1 isolates induce significantly greater interferon (IFN) $-\gamma$ production by peripheral blood mononuclear cells comparing to RST3 strains [44]. Infection of $\mathrm{C} 3 \mathrm{H} / \mathrm{HeJ}$ mice with RST1 strains resulted in more severe arthritis and carditis than did infection with RST3 isolates in a study performed by Wang et al. [45].

Spirochetal antigen OspC is a factor crucial for the invasion of a host [46]. OspC facilitates bacterial transmission with tick saliva during a bite by forming a complex with a tick salivary protein, Salp15 [47]. OspC is highly immunogenic and is one of the primary inductors of host immune response [48]. Moreover, it interacts with plasminogen which is likely to enable spirochetal dissemination to peripheral tissues [46].

Through its surface molecules, B. burgdorferi is able to bind host proteins and, in that way, hide from the host immune system. As reviewed by Nardelli et al., it can bind to fibronectin, type I collagen, glycosaminoglycans, proteoglycans and integrins [49].

B. burgdorferi has also been shown to rapidly inhibit human complement by binding host complement regulators (such as FH, FHR-1, C4Bp, C1r, C7, C8, C9, TCC) through a family of surface-exposed molecules (CspA, CspZ, ErpP, ErpC, ErpA, p43, BBK32, BGA66, BGA71 and CD59-like protein) [50].

Additionally, B. burgdorferi produces protease with aggrecanase activity, which is postulated by Russell et al. to be involved in direct mechanism of tissue damage in LA [51].

There is also evidence of roles for several constituents of tick saliva. Prostaglandin E2 inhibits the production of the $\mathrm{T}$ helper (Th)1-associated cytokines interleukin (IL)-12 and tumor necrosis factor (TNF)- $\alpha$ by dendritic cells in an infection site [52]. B-cell inhibitory protein and sialostatin $\mathrm{L}$ are also involved in local suppression of immune response [53, 54].

\section{Immunological background}

Presence of spirochetes at synovial sites triggers development of joint inflammation (Fig. 3) characterized by effusion dominated with neutrophils. As they bind spirochetal lipoprotein to Toll-like receptor 2 [55], neutrophils produce proinflammatory cytokines: IL- 1 , TNF- $\alpha$, IL- 8 and IL-15 [49]. They can also eliminate spirochetes through phagocytosis [56].

Additionally, spirochetal stimulation of macrophages results in release of proinflammatory mediators typical for M1 macrophages, namely: TNF- $\alpha$, IL-1 $\beta$, IL-12, IL18 and nitric oxide [57].

Subsequently, development of joint inflammation involves Th1 lymphocytes. Activated T lymphocytes from $\mathrm{LD}$ patients produce IFN- $\gamma$ following ex vivo stimulation with $B$. burgdorferi constituents [58]. In addition, IFN- $\gamma$ and IFN-responsive genes are expressed in the joints of B. burgdorferi-infected mice [59, 60]. Surprisingly, the levels of IFN- $\gamma$ did not correlate with the severity of other symptoms in a study performed by Callister et al. [61].

Zeidner et al. found that treating mice with the Th1associated cytokines TNF- $\alpha$ and IFN- $\gamma$ during tick feeding provided a 95 and $55 \%$ protection rate against transmission, respectively [62]. 


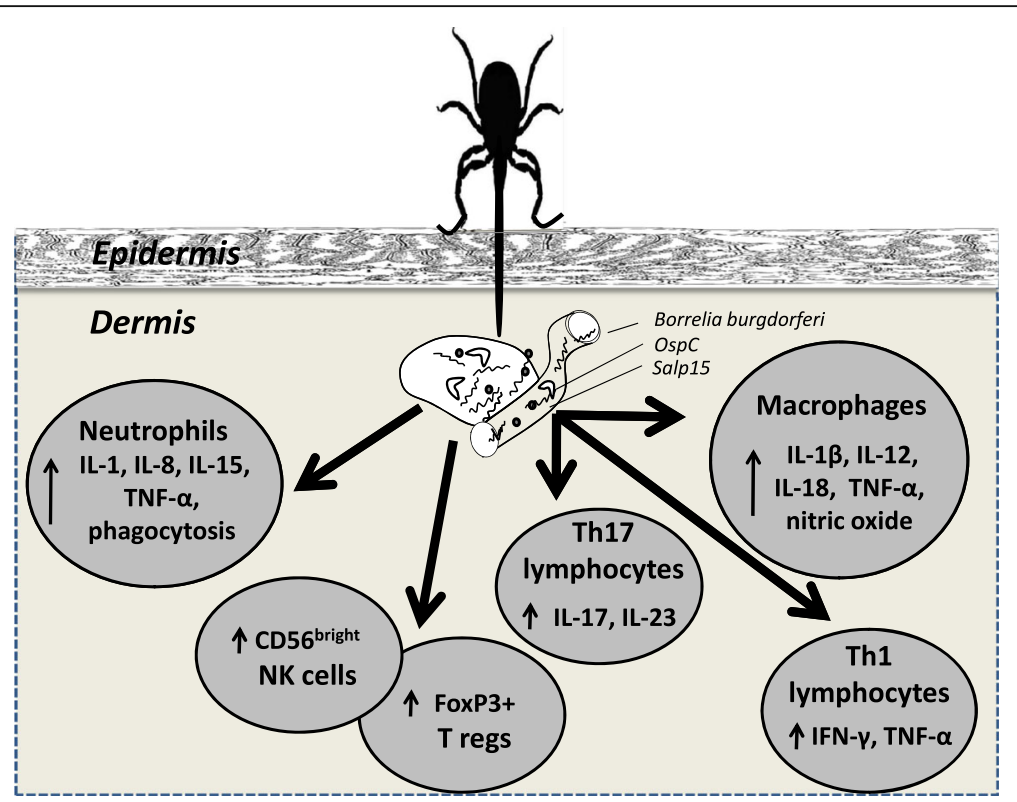

Fig. 3 Set of changes in cytokine profile and concentrations of cells in the pathogenesis of LA; abbreviations explained in the text

Th1-related inflammation is not the only possible immunological route of developing LA. B. burgdorferi has been shown to be a strong inducer of IL-10 which inhibits Th1 activity and may contribute to the immune tolerance of the microbe [63].

Several studies reviewed by Kuo et al. showed that arthritis observed in IFN- $\gamma$-deficient mice was dependent on IL-17 [64]. Infante-Duarte et al. reported compatible results in humans [65]. However, Bachmann et al. did not observe production of IL-17 by $B$. burgdorferi-stimulated human peripheral blood mononuclear cells [66].

Production of IL-17, as well as another Th17-supporting cytokine, IL-23, is induced by borrelial neutrophil activating protein A (NapA) [67]. There is mounting evidence that levels of these cytokines tend to be elevated in patients with severe, persisting symptoms, namely in antibiotic-refractory LA $[67,68]$.

Patients with LA have also high frequencies of CD56bright natural killer (NK) cells in synovial fluid [69]. It has been suggested that CD56bright NK cells may either exacerbate or regulate immune responses [70]. Presence of CD56bright NK cells producing IFN- $\gamma$ in synovial fluid suggests that these cells contribute to elimination of spirochetes [52]. Barthold et al. reported less severe LA in mice genetically deficient in granulocytes and NK cells [71].

FoxP3+ regulatory $\mathrm{T}$ cells in synovial fluid also play a role in LA [72]. Low frequencies of FoxP3+ regulatory $\mathrm{T}$ cells in synovial fluid lead to slower arthritis resolution $[73,74]$.
The progression into antibiotic-refractory LA is presumably independent of persistent spirochetal infection. Underlying autoimmune background has been postulated by Steere et al. [75]. There are seven human leukocyte antigen-D-related (HLA-DR) alleles identified, including the DRB1*0101, 0401 and 1501 alleles, that are predominant in patients with antibiotic-refractory patients [76]. Moreover, Arvikar et al. listed 4 Lymeassociated autoantigens that are more frequent in the aforementioned group [77]. They include: endothelial cell growth factor (ECGF), apolipoprotein B-100 (apoB100), matrix metalloproteinase-10 (MMP-10) and annexinA2. Of these, only the response to annexin-A2 is not LA-specific, as it is elevated in both LA and RA [78].

\section{Diagnostics}

The current diagnostic standard of LA requires both clinical and laboratory criteria [79]. Laboratory testing relies predominantly on serology. Overall, a two-step approach is recommended: initial screening with an enzymelinked immunosorbent assay (ELISA) followed by a supplemental Western immunoblot test (WB) in case the first step is positive [80]. In the United States, current criteria for a positive WB established by $\mathrm{CDC}$ require the presence of 2 (of 3) specified bands on the IgM WB or 5 (of 10) specified bands on the IgG WB [81]. There are also several other types of immunoblotting assays (including the EUROIMMUN Anti-Borrelia EUROLINE-WB which is frequently utilized in Europe) with variation in antigen composition and modified interpretation criteria which are provided by the producers [82]. 
Patients with signs and symptoms $\leq 30$ days may be considered positive based on either IgM or IgG, whereas those with signs and symptoms $>30$ days, that is the majority of patients with LA, require IgG positivity [83]. Serology results may be falsely positive due to cross-reactivity, especially in patients with infectious mononucleosis [84] or in the presence of rheumatoid factor (RF) [7].

The diagnostic value of testing LA patients for IgM is questionable. A positive IgM WB may be falsely positive, particularly if a patient has manifested symptoms for more than 1 month [85]. Sensitivity of IgM testing in LA patients assessed by Leeflang et al. was insufficient (0.392) to be considered reliable, whereas IgG testing was sensitive enough (0.941) to be informative [86]. Specificity of IgM and IgG was comparable: 0.951 and 0.969 , respectively.

Serology results are inadequate to monitor the treatment of LA [7]. It may be expected that some individuals with LA will be found to have positive IgM WB months to years later, due to the persistence of OspCspecific antibody response [87]. Polymerase chain reaction (PCR) on synovial fluid performed no sooner than 2 months after treatment is postulated to serve as a marker of eradication of spirochetes [87]. However, it is not yet properly standardized to use routinely in the diagnostic process [88].

There are several limitations of WB which affect the results of the standard two-tier test. As reviewed by Branda et al., it is insensitive in early phase of LD due to slow development of the humoral immune response [89]. Moreover, it is a complex procedure with a potential risk of false results influenced by subjective visual scoring. Therefore it frequently needs to be performed at reference laboratories and, for that reason, it consumes more time and expenses [90].

A newer, first-step ELISA, the C6 antibody test, uses a peptide from the constant region of a B. burgdorferi protein called Vmp-like sequence lipoprotein E (VlsE) [91]. Anti-VlsE antibodies develop early therefore C6 test provides comparable to higher sensitivity than a standard two-tier test [84, 92]. As it is less timeconsuming than a standard two-tier test, it may be helpful in early decision whether to consider treatment [92]. Nevertheless, C6 seroprevalence in healthy blood donors tends to be high in endemic areas [93].

Branda et al. postulated an alternative diagnostic algorithm, in which WB is replaced by C6 ELISA as the second step in modified two-tier test (MTTT) [94]. As evaluated by Molins et al., it offered a simplified procedure as it was free of WB limitations. MTTT had enhanced sensitivity in diagnosing LD and was equivalent or significantly better than the standard algorithm [84]. Therefore this approach should be further investigated.

\section{Treatment}

According to current recommendations (B/III level) from the Infectious Diseases Society of America (IDSA), children with LA should be treated initially with a 28-day course of oral antibiotics: doxycycline $4 \mathrm{mg} / \mathrm{kg}$ per day in 2 divided doses (maximum of $100 \mathrm{mg}$ per dose), cefuroxime axetil $30 \mathrm{mg} / \mathrm{kg}$ per day in 2 divided doses (maximum of $500 \mathrm{mg}$ per dose) or amoxicillin $50 \mathrm{mg} / \mathrm{kg}$ per day in 3 divided doses (maximum of $500 \mathrm{mg}$ per dose) [35]. Doxycycline is typically preferred because of its activity against B. burgdorferi sensu lato. However, doxycycline is not recommended for children $<8$ years of age due to its contribution to discoloration of teeth [95].

In patients who are still symptomatic after the recommended treatment, another 4-week course of oral antibiotics or a 2-4-week course of intravenous ceftriaxone should be administered [35]. Nevertheless, there is no benefit in further prolongation of antibiotic therapy. In a study performed by Berende et al. there was no significant difference of health-related quality of life between groups of patients who received 2 weeks of intravenous ceftriaxone and then continued treatment with a 12week course of oral doxycycline, clarithromycin plus hydroxychloroquine or placebo [96].

As even antibiotic-refractory cases of LA were shown by Steere et al. to eventually improve [31], further treatment is questionable. In persistent cases, symptomatic therapies with non-steroidal anti-inflammatory drugs (NSAIDs), disease-modifying antirheumatic drugs (DMARDs), or intra-articular corticosteroids are recommended in the United States according to the IDSA [35]. Oral or intra-articular corticosteroids are contraindicated until antibiotic treatment is completed since these drugs permit greater growth of spirochetes [97], and because intra-articular steroid injections were reported to prolong duration of LA [3]. DMARDs are typically prescribed for only 6-12 months rather than indefinitely as in the treatment of patients with JIA. Arthroscopic synovectomy may be an option when pharmacotherapy is eventually ineffective [98].

Spirochetal infection provides plethora of potential therapeutic targets for new designer drugs [99]. These include, among others: ClpP protease which is upregulated by spirochetal persister cells [100] and HtrA protease which plays a role in pathogenicity of B. burgdorferi [101].

\section{Conclusions}

The clinical picture of LA resembles a classic autoimmune arthritis, similar to other rheumatoid disease, with immunomodulation and tissue damage. The active infection requiring antibiotic treatment is a factor that constitutes the essential difference. As a single-centre experience, the authors recommend ELISA screening in all patients suspected with JIA in regions endemic for 
LD. As WB confirmation may be time-consuming, simultaneous two-tier testing is advisable when patient's history suggests a possibility of potential tick bite.

New diagnostic approaches should be elaborated on to evaluate their relevance. The assessment of the $\mathrm{C} 6$ antibody test in children is particularly essential for the future progress in diagnostic process and therapy.

Development of consistent worldwide guidelines would simplify diagnostic process in everyday pediatric practice.

\begin{abstract}
Abbreviations
apoB-100: apolipoprotein B-100; B. burgdorferi: Borrelia burgdorferi; CDC: The centers for disease control and prevention; DMARDs: Disease modifying antirheumatic drugs; ECGF: Endothelial cell growth factor; ELISA: Enzymelinked immunosorbent assay; EM: Erythema migrans; HLA-DR: Human leukocyte antigen-D-related; IDSA: Infectious diseases society of America; IFN-Y: Interferon gamma; IL: Interleukin; JIA: Juvenile idiopathic arthritis; LA: Lyme arthritis; LD: Lyme disease; MMP-10: metalloproteinase 10; MTTT: Modified two-tier test; NapA: Neutrophil activating protein A; NK: Natural killer; NSAIDs: Non-steroidal anti-inflammatory drugs; OspC: Outer surface protein C; PCR: Polymerase chain reaction; RF: Rheumatoid factor; RST: Ribosomal spacer type; Th: T helper; TNF-a: Tumor necrosis factor alpha; VlsE: Vmp-like sequence lipoprotein $\mathrm{E}$; WB: Western immunoblot test
\end{abstract}

\section{Acknowledgements}

Not applicable

\section{Funding}

This work was partially the grant from Medical University of Lodz, Poland No. 502-03/8-000/01/502-64-094.

\section{Availability of data and materials}

Not applicable.

\section{Authors' contributions}

$\mathrm{KO}$ and JSJ collected literature and prepared manuscript with equal contribution. ES supervised the content of the manuscript and provided images. All authors read and approved the final manuscript.

\section{Competing interests}

The authors declare that they have no competing interests.

\section{Consent for publication}

Authors obtained parents' consent for publication of images.

\section{Ethics approval and consent to participate}

Not applicable.

\section{Publisher's Note}

Springer Nature remains neutral with regard to jurisdictional claims in published maps and institutional affiliations.

Received: 9 March 2017 Accepted: 1 May 2017

Published online: 08 May 2017

\section{References}

1. Steere AC, Broderick TF, Malawista SE. Erythema chronicum migrans and Lyme arthritis: epidemiologic evidence for a tick vector. Am J Epidemiol. 1978:108:312-21.

2. Torbahn $\mathrm{G}$, Hofmann $\mathrm{H}$, Allert R, et al. Efficacy and safety of pharmacological agents in the treatment of erythema migrans in early Lyme borreliosissystematic review protocol. Syst Rev. 2016;5:73.

3. Arvikar SL, Steere AC. Diagnosis and treatment of Lyme arthritis. Infect Dis Clin North Am. 2015;29:269-80

4. Steere AC, Malawista SE, Snydman DR, et al. Lyme arthritis: an epidemic of oligoarticular arthritis in children and adults in three connecticut communities. Arthritis Rheum. 1977;20:7-17.
5. Steere AC, Bartenhagen NH, Craft JE, et al. The early clinical manifestations of Lyme disease. Ann Intern Med. 1983;99:76-82.

6. Gryczynska A, Welc-Faleciak R. Long-term study of the prevalence of Borrelia burgdorferi s.l. infection in ticks (Ixodes ricinus) feeding on blackbirds (Turdus merula) in NE Poland. Exp Appl Acarol. 2016;70:381-94.

7. Kmieciak W, Ciszewski M, Szewczyk EM. Tick-borne diseases in Poland: Prevalence and difficulties in diagnostics [in Polish]. Med Pr. 2016;67:73-87.

8. Kocbach PP, Kocbach BP. Prevalence of Lyme disease among forestry workers [in Polish]. Med Pr. 2014;65:335-41.

9. Cerar T, Strle F, Stupica D, et al. Differences in genotype, clinical features, and inflammatory potential of borrelia burgdorferi sensu stricto strains from Europe and the United States. Emerging Infect Dis. 2016;22:818-27.

10. van Dam AP, Kuiper H, Vos K, et al. Different genospecies of Borrelia burgdorferi are associated with distinct clinical manifestations of Lyme borreliosis. Clin Infect Dis. 1993;17:708-17.

11. Stanek G, Reiter M. The expanding Lyme Borrelia complex-clinical significance of genomic species? Clin Microbiol Infect. 2011;17:487-93.

12. Jaenson $T G$, Jaenson $D G$, Eisen $L$, Petersson $E$, Lindgren $E$. Changes in the geographical distribution and abundance of the tick Ixodes ricinus during the past 30 years in Sweden. Parasit Vectors. 2012;5:8.

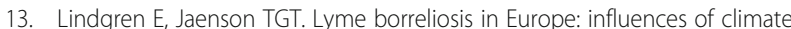
and climate change, epidemiology, ecology and adaptation measures. WHO Europe. 2006. http://www.euro.who.int/_data/assets/pdf_file/0006/96819/ E89522.pdf. Accessed 22 Dec 2016.

14. Sykes RA, Makiello P. An estimate of Lyme borreliosis incidence in Western Europe. J Public Health (Oxf). 2016. doi:10.1093/pubmed/fdw017.

15. Centers for Disease Control and Prevention (CDC). Summary of notifiable diseases, United States, 2008. MMWR Morb Mortal Wkly Rep. 2010;57:19.

16. Hinckley AF, Connally NP, Meek Jl, et al. Lyme disease testing by large commercial laboratories in the United States. Clin Infect Dis. 2014;59:676-81.

17. Czupryna P, Moniuszko-Malinowska A, Pancewicz S, et al. Lyme disease in Poland - A serious problem? Adv Med Sci. 2016;61:96-100.

18. Sadkowska-Todys M, Zielinski A, Czarkowski MP. Infectious diseases in Poland in 2014 [in Polish]. Przegl Epidemiol. 2016;70:167-81.

19. Zeman P, Benes C. Spatial distribution of a population at risk: an important factor for understanding the recent rise in tick-borne diseases (Lyme borreliosis and tick-borne encephalitis in the Czech Republic). Ticks Tick Borne Dis. 2013:4:522-30.

20. Richter D, Schlee DB, Matuschka FR. Reservoir competence of various rodents for the lyme disease Spirochete Borrelia spielmanii. Appl Environ Microbiol. 2011;77(11):3565-70

21. Borchers AT, Keen CL, Huntley AC, Gershwin ME. Lyme disease: a rigorous review of diagnostic criteria and treatment. J Autoimmun. 2015;57:82-115.

22. Sood SK, Salzman MB, Johnson BJ, et al. Duration of tick attachment as a predictor of the risk of Lyme disease in an area in which Lyme disease is endemic. J Infect Dis. 1997;175:996-9.

23. Hodzic E, Feng S, Freet KJ, Borjesson DL, Barthold SW. Borrelia burgdorferi population kinetics and selected gene expression at the host-vector interface. Infect Immun. 2002;70:3382-8.

24. Aenishaenslin C, Bouchard C, Koffi JK, Ogden NH. Exposure and preventive behaviours toward ticks and Lyme disease in Canada: Results from a first national survey. Ticks Tick Borne Dis. 2016. doi:10.1016/j.ttbdis.2016.10.006.

25. Pancewicz SA, Rutkowski R, Rutkowski K, Zajkowska J, Kondrusik M. Immunopathology of Lyme Arthrites [in Polish]. Pol Merk Lek. 2007;134:141-4.

26. Centers for Disease Control and Prevention (CDC). Lyme disease-United States, 2001-2002. MMWR Morb Mortal Wkly Rep. 2004;53:365-9.

27. Deanehan JK, Kimia AA, Tan tanny SP, et al. Distinguishing Lyme from septic knee monoarthritis in Lyme disease-endemic areas. Pediatrics. 2013:131:e695-701.

28. Bachur RG, Adams CM, Monuteaux MC. Evaluating the child with acute hip pain ("irritable hip") in a Lyme endemic region. J Pediatr. 2015;166:407-11.e1.

29. Devauchelle-Pensec V, Thepaut M, Pecquery R, Houx L. Managing monoarthritis in children. Joint Bone Spine. 2016;83:25-30.

30. Glaude PD, Huber AM, Mailman T, Ramsey S, Lang B, Stringer E. Clinical characteristics, treatment and outcome of children with Lyme arthritis in Nova Scotia. Paediatr Child Health. 2015;20:377-80.

31. Steere AC, Schoen RT, Taylor E. The clinical evolution of Lyme arthritis. Ann Intern Med. 1987;107(5):725-31.

32. Szer IS, Taylor E, Steere AC. The long-term course of Lyme arthritis in children. N Engl J Med. 1991;325:159-63. 
33. Daikh BE, Emerson FE, Smith RP, Lucas FL, McCarthy CA. Lyme arthritis: a comparison of presentation, synovial fluid analysis, and treatment course in children and adults. Arthritis Care Res (Hoboken). 2013;65:1986-90.

34. Miller JR, Dunn KW, Braccia D, et al. Lyme disease manifestations in the foot and ankle: a retrospective case series. J Foot Ankle Surg. 2016;55:1241-4.

35. Wormser GP, Dattwyler RJ, Shapiro ED, et al. The clinical assessment, treatment, and prevention of lyme disease, human granulocytic anaplasmosis, and babesiosis: clinical practice guidelines by the Infectious Diseases Society of America. Clin Infect Dis. 2006:43:1089-134.

36. Huppertz HI, Karch H, Suschke HJ, et al. Lyme arthritis in European children and adolescents. The pediatric rheumatology collaborative group. Arthritis Rheum. 1995;38:361-8

37. Thompson A, Mannix R, Bachur R. Acute pediatric monoarticular arthritis: distinguishing lyme arthritis from other etiologies. Pediatrics. 2009;123:959-65.

38. Aiyer A, Hennrikus W, Walrath J, Groh B, Ostrov B. Lyme arthritis of the pediatric lower extremity in the setting of polyarticular disease. J Child Orthop. 2014;8:359-65.

39. Sá MC, Moreira C, Melo C, Sousa Á, Carvalho S. Lyme disease and juvenile idiopathic arthritis - A pediatric case report. Rev Bras Reumatol. 2015. doi:10.1016/j.rbr.2015.08.003.

40. Steere AC, Levin RE, Molloy PJ, et al. Treatment of Lyme arthritis. Arthritis Rheum. 1994;37:878-88.

41. Tory HO, Zurakowski D, Sundel RP. Outcomes of children treated for Lyme arthritis: results of a large pediatric cohort. J Rheumatol. 2010;37:1049-55.

42. Bennet $L$, Berglund J. Reinfection with Lyme borreliosis: a retrospective follow-up study in southern Sweden. Scand J Infect Dis. 2002;34:183-6.

43. Schnarr S, Franz JK, Krause A, Zeidler H. Infection and musculoskeletal conditions: Lyme borreliosis. Best Pract Res Clin Rheumatol. 2006;20:1099-118.

44. Strle K, Jones KL, Drouin EE, Li X, Steere AC. Borrelia burgdorferi RST1 (OspC type A) genotype is associated with greater inflammation and more severe Lyme disease. Am J Pathol. 2011;178:2726-39.

45. Wang G, Ojaimi C, Wu H, et al. Disease severity in a murine model of lyme borreliosis is associated with the genotype of the infecting Borrelia burgdorferi sensu stricto strain. J Infect Dis. 2002;186:782-91.

46. Edmondson DG, Prabhakaran S, Norris SJ, et al. Enhanced protective immunogenicity of homodimeric Borrelia burgdorferi Outer Surface Protein C. Clin Vaccine Immunol. 2016. doi:10.1128/CVI.00306-16.

47. Ramamoorthi N, Narasimhan S, Pal U, et al. The Lyme disease agent exploits a tick protein to infect the mammalian host. Nature. 2005;436:573-7.

48. Fung $B P$, Mchugh $G L$, Leong JM, Steere AC. Humoral immune response to outer surface protein $C$ of Borrelia burgdorferi in Lyme disease: role of the immunoglobulin $\mathrm{M}$ response in the serodiagnosis of early infection. Infect Immun. 1994:62:3213-21.

49. Nardelli DT, Callister SM, Schell RF. Lyme arthritis: current concepts and a change in paradigm. Clin Vaccine Immunol. 2008;15:21-34.

50. Kraiczy P. Hide and seek: how Lyme disease spirochetes overcome complement attack. Front Immunol. 2016:7:385.

51. Russell TM, Johnson BJ. Lyme disease spirochaetes possess an aggrecanbinding protease with aggrecanase activity. Mol Microbiol. 2013;90:228-40.

52. Sjöwall J, Fryland L, Nordberg M, et al. Decreased Th1-type inflammatory cytokine expression in the skin is associated with persisting symptoms after treatment of erythema migrans. PLOS ONE. 2011;6:e18220.

53. Hannier S, Liversidge J, Sternberg JM, Bowman AS. Characterization of the B-cell inhibitory protein factor in Ixodes ricinus tick saliva: a potential role in enhanced Borrelia burgdoferi transmission. Immunology. 2004;113:401-8.

54. Kotsyfakis M, Sá-Nunes A, Francischetti IM, Mather TN, Andersen JF, Ribeiro JM. Antiinflammatory and immunosuppressive activity of sialostatin L, a salivary cystatin from the tick Ixodes scapularis. J Biol Chem. 2006;281:26298-307.

55. Parker LC, Whyte MK, Dower SK, Sabroe I. The expression and roles of Toll-like receptors in the biology of the human neutrophil. J Leukoc Biol. 2005;77:886-92.

56. Szczepanski A, Fleit HB. Interaction between Borrelia burgdorferi and Polymorphonuclear Leukocytes. Ann NY Acad Sci. 1988;539:425-8.

57. Swidrowska-Jaros J, Orczyk K, Smolewska E. Macrophages - silent enemies in juvenile idiopathic arthritis. Postepy Hig Med Dosw (Online). 2016;70:743-50.

58. Jin C, Roen DR, Lehmann PV, Kellermann GH. An enhanced ELISPOT assay for sensitive detection of antigen-specific T cell responses to borrelia burgdorferi. Cells. 2013;2:607-20.

59. Crandall H, Dunn DM, Ma Y, et al. Gene expression profiling reveals unique pathways associated with differential severity of lyme arthritis. J Immunol. 2006;177:7930-42
60. Miller JC, Ma Y, Bian J, et al. A critical role for type I IFN in arthritis development following Borrelia burgdorferi infection of mice. J Immunol. 2008;181:8492-503.

61. Callister SM, Jobe DA, Stuparic-Stancic A, et al. Detection of IFN- $\gamma$ secretion by T cells collected before and after successful treatment of early Lyme disease. Clin Infect Dis. 2016;62:1235-41.

62. Zeidner N, Dreitz M, Belasco D, Fish D. Suppression of acute Ixodes scapularisinduced Borrelia burgdorferi infection using tumor necrosis factor-alpha, interleukin-2, and interferon-gamma. J Infect Dis. 1996;173:187-95.

63. Sonderegger FL, Ma Y, Maylor-hagan H, et al. Localized production of IL-10 suppresses early inflammatory cell infiltration and subsequent development of IFN- $\gamma$-mediated Lyme arthritis. J Immunol. 2012;188:1381-93.

64. Kuo J, Warner TF, Munson EL, Nardelli DT, Schell RF. Arthritis is developed in Borrelia-primed and -infected mice deficient of interleukin-17. Pathog Dis. 2016. doi:10.1093/femspd/ftw077.

65. Infante-Duarte C, Horton HF, Byrne MC, Kamradt T. Microbial lipopeptides induce the production of IL-17 in Th cells. J Immunol. 2000;165:6107-15.

66. Bachmann M, Horn K, Rudloff I, et al. Early production of IL-22 but not IL-17 by peripheral blood mononuclear cells exposed to live Borrelia burgdorferi: the role of monocytes and interleukin-1. PLoS Pathog. 2010;6:e1001144.

67. Codolo G, Amedei A, Steere AC, et al. Borrelia burgdorferi NapA-driven Th17 cell inflammation in lyme arthritis. Arthritis Rheum. 2008;58:3609-17.

68. Strle K, Stupica D, Drouin EE, Steere AC, Strle F. Elevated levels of IL-23 in a subset of patients with post-lyme disease symptoms following erythema migrans. Clin Infect Dis. 2014;58:372-80.

69. Katchar K, Drouin EE, Steere AC. Natural killer cells and natural killer T cells in Lyme arthritis. Arthritis Res Ther. 2013;15:R183.

70. Pausa $M$, Pellis V, Cinco M, et al. Serum-resistant strains of Borrelia burgdorferi evade complement-mediated killing by expressing a CD59-like complement inhibitory molecule. J Immunol. 2003;170:3214-22.

71. Barthold SW, De Souza M. Exacerbation of Lyme arthritis in beige mice. J Infect Dis. 1995;172:778-84.

72. Hori S, Nomura T, Sakaguchi S. Control of regulatory T cell development by the transcription factor Foxp3. Science. 2003;299:1057-61.

73. Vudattu NK, Strle K, Steere AC, Drouin EE. Dysregulation of CD4 + CD25(high) T cells in the synovial fluid of patients with antibiotic-refractory Lyme arthritis. Arthritis Rheum. 2013:65:1643-53.

74. Shen S, Shin JJ, Strle K, et al. Treg cell numbers and function in patients with antibiotic-refractory or antibiotic-responsive Lyme arthritis. Arthritis Rheum. 2010;62:2127-37.

75. Steere AC, Glickstein L. Elucidation of Lyme arthritis. Nat Rev Immunol. 2004;4:143-52.

76. Steere AC, Klitz W, Drouin EE, et al. Antibiotic-refractory Lyme arthritis is associated with HLA-DR molecules that bind a Borrelia burgdorferi peptide. J Exp Med. 2006:203:961-71.

77. Arvikar SL, Crowley JT, Sulka KB, Steere AC. Autoimmune arthritides, rheumatoid arthritis, psoriatic arthritis, or peripheral spondyloarthropathy, following lyme disease. Arthritis Rheumatol. 2016. doi:10.1002/art.39866.

78. Pianta A, Drouin EE, Crowley JT, et al. Annexin A2 is a target of autoimmune T and $B$ cell responses associated with synovial fibroblast proliferation in patients with antibiotic-refractory Lyme arthritis. Clin Immunol. 2015;160:336-41.

79. Lipsett SC, Nigrovic LE. Diagnosis of Lyme disease in the pediatric acute care setting. Curr Opin Pediatr. 2016;28:287-93.

80. Hu LT. Lyme disease. Ann Intern Med. 2016;165:677.

81. Fallon BA, Pavlicova M, Coffino SW, Brenner C. A comparison of lyme disease serologic test results from 4 laboratories in patients with persistent symptoms after antibiotic treatment. Clin Infect Dis. 2014;59:1705-10.

82. Ang CW, Notermans DW, Hommes M, Simoons-smit AM, Herremans T. Large differences between test strategies for the detection of anti-Borrelia antibodies are revealed by comparing eight ELISAs and five immunoblots. Eur J Clin Microbiol Infect Dis. 2011;30(8):1027-32.

83. Centers for Disease Control and Prevention (CDC). Recommendations for test performance and interpretation from the Second National Conference on Serologic Diagnosis of Lyme Disease. MMWR Morb Mortal Wkly Rep. 1995:44:590-1.

84. Molins CR, Delorey MJ, Sexton C, Schriefer ME. Lyme borreliosis serology: performance with several commonly used laboratory diagnostic tests and a large resource panel of well-characterized patient samples. J Clin Microbiol. 2016. doi:10.1128/JCM.00874-16.

85. Seriburi V, Ndukwe N, Chang Z, Cox ME, Wormser GP. High frequency of false positive lgM immunoblots for Borrelia burgdorferi in clinical practice. Clin Microbiol Infect. 2012;18:1236-40. 
86. Leeflang MM, Ang CW, Berkhout J, et al. The diagnostic accuracy of serological tests for Lyme borreliosis in Europe: a systematic review and meta-analysis. BMC Infect Dis. 2016;16:140.

87. Pawinska A. Lyme borreliosis - microbiological diagnostics and treatment [in Polish]. Stand Med Pediatr. 2009;6:757-66.

88. Flisiak R, Pancewicz S. Diagnostics and treatment of Lyme borreliosis. Recommendations of Polish Society of Epidemiology and Infectious Diseases [in Polish]. Department of Infectious Diseases and Hepatology Medical University of Bialystok. 2011. http://www.choroby-zakazne.pl/ uploads/pdf/borelioza.pdf. Accessed 22 Dec 2016.

89. Branda JA, Strle K, Nigrovic LE, et al. Evaluation of modified 2-tiered serodiagnostic testing algorithms for early Lyme disease. Clin Infect Dis. 2017;64(8):1074-80.

90. Wormser GP, Levin A, Soman S, Adenikinju O, Longo MV, Branda JA. Comparative cost-effectiveness of two-tiered testing strategies for serodiagnosis of lyme disease with noncutaneous manifestations. J Clin Microbiol. 2013;51(12):4045-9.

91. Bacon RM, Biggerstaff BJ, Schriefer ME, et al. Serodiagnosis of Lyme disease by kinetic enzyme-linked immunosorbent assay using recombinant VIsE1 or peptide antigens of Borrelia burgdorferi compared with 2-tiered testing using whole-cell lysates. J Infect Dis. 2003;187:1187-99.

92. Lipsett SC, Branda JA, Mcadam AJ, et al. Evaluation of the C6 Lyme enzyme immunoassay for the diagnosis of Lyme disease in children and adolescents. Clin Infect Dis. 2016;63(7):922-8.

93. Johansson M, Manfredsson L, Wistedt A, Serrander L, Tjernberg I. Significant variations in the seroprevalence of C6 ELISA antibodies in a highly endemic area for Lyme borreliosis: evaluation of age, sex and seasonal differences. APMIS. 2017. doi:10.1111/apm.12664.

94. Branda JA, Linskey K, Kim YA, Steere AC, Ferraro MJ. Two-tiered antibody testing for Lyme disease with use of 2 enzyme immunoassays, a whole-cell sonicate enzyme immunoassay followed by a VIsE C6 peptide enzyme immunoassay. Clin Infect Dis. 2011;53:541-7.

95. Barton-forbes M, Leonard E, Lindsay LR, Langley JM, Koffi JK, Ogden NH. Tick bites in the Lyme light. Paediatr Child Health. 2015;20:237-8.

96. Berende A, Ter Hofstede HJ, Vos FJ, et al. Randomized trial of longerterm therapy for symptoms attributed to Lyme disease. N Engl J Med. 2016:374:1209-20.

97. Pachner AR, Delaney E, O'neill T. Neuroborreliosis in the nonhuman primate: Borrelia burgdorferi persists in the central nervous system. Ann Neurol. 1995;38:667-9.

98. Schoen RT, Aversa JM, Rahn DW, Steere AC. Treatment of refractory chronic Lyme arthritis with arthroscopic synovectomy. Arthritis Rheum. 1991;34:1056-60.

99. Stricker RB, Johnson L. Lyme disease: the promise of Big Data, companion diagnostics and precision medicine. Infect Drug Resist. 2016;9:215-9.

100. Feng J, Shi W, Zhang S, Zhang Y. Persister mechanisms in Borrelia burgdorferi: implications for improved intervention. Emerg Microbes Infect. 2015;4:e51.

101. Gherardini FC. Borrelia burgdorferi HtrA may promote dissemination and irritation. Mol Microbiol. 2013;90:209-13.

\section{Submit your next manuscript to BioMed Central and we will help you at every step:}

- We accept pre-submission inquiries

- Our selector tool helps you to find the most relevant journal

- We provide round the clock customer support

- Convenient online submission

- Thorough peer review

- Inclusion in PubMed and all major indexing services

- Maximum visibility for your research

Submit your manuscript at www.biomedcentral.com/submit
Biomed Central 